\title{
Influence of substrate on corneal epithelial cell viability within ocular surface models
}

Article

Accepted Version

Feng, Y., Foster, J., Mi, S., Chen, B. and Connon, C. (2012) Influence of substrate on corneal epithelial cell viability within ocular surface models. Experimental Eye Research, 101. pp. 97-103. ISSN 0014-4835 doi: https://doi.org/10.1016/j.exer.2012.05.005 Available at https://centaur.reading.ac.uk/28136/

It is advisable to refer to the publisher's version if you intend to cite from the work. See Guidance on citing.

To link to this article DOI: http://dx.doi.org/10.1016/j.exer.2012.05.005

Publisher: Elsevier

All outputs in CentAUR are protected by Intellectual Property Rights law, including copyright law. Copyright and IPR is retained by the creators or other copyright holders. Terms and conditions for use of this material are defined in the End User Agreement.

\section{www.reading.ac.uk/centaur}

\section{CentAUR}

Central Archive at the University of Reading 
Reading's research outputs online 


\title{
Influence of substrate on corneal epithelial cell viability within ocular surface models
}

\author{
Yun Feng ${ }^{1,2}$, James Foster ${ }^{1}$, Shengli $\mathrm{Mi}^{1}$, Bo Chen ${ }^{1}$, Che John Connon ${ }^{1}$ \\ ${ }^{1}$ School of Pharmacy, University of Reading, United Kingdom \\ ${ }^{2}$ Peking University $3^{\text {rd }}$ Hospital, Peking University Eye Center \\ Corresponding author: Che John Connon \\ Telephone: +44-0118378 7053; \\ Fax: $\quad+\mathbf{4 4 8 7 1 2 5 1 4 6 6 5}$
}

Email: c.j.connon@reading.ac.uk

\begin{abstract}
Corneal tissue engineering has improved dramatically over recent years. It is now possible to apply these technological advancements to the development of superior in vitro ocular surface models to reduce animal testing. We aim to show the effect different substrates can have on the viability of expanded corneal epithelial cells and that those which more accurately mimic the stromal surface provide the most protection against toxic assault. Compressed collagen gel as a substrate for the expansion of a human epithelial cell line was compared against two wellknown substrates for modeling the ocular surface (polycarbonate membrane and conventional collagen gel). Cells were expanded over 10 days at which point cell stratification, cell number and expression of junctional proteins were assessed by electron microscopy, immunohistochemistry and RT-PCR. The effect of increasing concentrations of sodium lauryl sulphate on epithelial cell viability was quantified by MTT assay. Results showed improvement in terms of stratification, cell number and tight junction expression in human epithelial cells expanded upon either the polycarbonate membrane or compressed collagen gel when compared to a the use of a conventional collagen gel. However, cell viability was significantly higher in cells expanded upon the compressed collagen gel. We conclude that the more
\end{abstract}


naturalistic composition and mechanical properties of compressed collagen gels produces a more robust corneal model.

\section{Introduction}

Since the 1940s, the accepted method for the assessment of acute eye irritation potential has been the Draize eye irritation test using a rabbit model (Draize, J.H. et al., 1944). However, the recent increase in experimental animal use, severity of the test and its limitations continues to present valid reasons for the sustained pursuit of alternative methods for ocular surface toxicity assessment.

In vitro alternatives to the Draize method needs to allow for the testing of chemicals, cosmetics and pharmaceutical drugs under conditions similar to the in vivo environment. Two validated ex vivo models are now accepted that identify severe eye irritants, namely the Bovine Corneal Opacity and Permeability (BCOP) and the Isolated Chicken Eye (ICE) test methods (European Commission, 2007). The bovine corneal opacity and permeability (BCOP) assay is an accepted alternative, but its accuracy is limited to less common severe irritants. In recent years, three dimensional human corneal constructs in cell culture have been reported to be useful models for assessment of irritancy potential (Doucet et al., 1998, 2006). More recently Nguyen et al. constructed a three-dimensional model using human corneal cells seeded on polycarbonate membrane resulting in a stratified human cornea epithelium with appropriate morphology and thickness (Nguyen et al., 2003). This model has subsequently been shown to be a useful alternative to the classic Draize test as it was able to predict the eye irritation potential of several established formulae belonging to various product types (Doucet, O. et al., 2006; Seaman, C.W. et al., 2010). However, this model does not consider the effect of the substrates mechanical properties on subsequent cell phenotype. It is now more widely recognized that cells migrate towards stiffer substrates (Pelham and Wang 1997) and that increased stiffness increases differentiation (Engler, AJ et al., 2006; Matthias, P. et al., 2009; Discher, D. E. et al., 2009; Gilbert, P.M. et al., 2010). These findings indicate that simply growing cells on tissue culture dishes or a thin polycarbonate membrane with an elastic modulus many times greater 
than the in vivo situation is likely to have a profound effect on the cells phenotype and function including the effective formation of a cell barrier to toxic assault. Therefore we posit that seeding the corneal epithelial cells on to a more physiologically relevant substrate, in terms of its constituent and mechanical properties, will lead to be a better ocular model for toxicity testing.

Collagen gels have been extensively studied as cell substrates for corneal cell growth due to their excellent biocompatibility (Kato, M. et al., 2007; Doillon, CJ. et al., 2003; Duan, X. et al., 2006; Crabb, RA. et al., 2006; Mi, S. et al., 2010a; Li, F. et al.,2005). Matsuda et al. developed a rabbit corneal epithelium model using cultured rabbit corneal epithelial cells on a collagen gel scaffold to evaluate eye irritants in vitro (Matsuda et al., 2009). However, the greatly hydrated nature of this type of conventional collagen gel results in highly dispersed collagen fibers and a gel that is both inherently weak and difficult to manipulate (Kato, M. et al., 2007; Mi, S. et al., 2011; Li, F. et al., 2005). Recently, we successfully expanded bovine corneal epithelial stem cells on compressed collagen gels. These compressed collagen gels are denser, mechanically stronger and stiffer than conventional collagen gels and their resultant ultra-structure more closely resembles the normal corneal stroma (Mi, S. et al., 2010a; Mi, S. et al., 2010b).

Furthermore, the subsequent expansion of corneal stem cells produced a tissue construct with improved cell density, cell stratification and levels of differentiation similar to the normal cornea (Jones, RR et al., 2012). We now hypothesize that the more naturalistic growth of corneal cells on compressed collagen gels could be used for in vitro toxicity testing thereby forming an improvement over the established models including conventional (uncompressed) collagen gels or standard tissue culture plastic (e.g. polycarbonate membranes) as substrates.

\section{Materials and methods}

\subsection{Cell culture}

Immortalised Simian virus 40-transformed human corneal epithelial (HCE) cells (Araki-Sasaki, K et al., 1995) were obtained from RIKEN Biosource Center (Tsukuba, Japan). The cells were 
maintained in supplemented hormonal epithelial medium (SHEM), which comprises Dulbecco's modified Eagle's medium (DMEM)-F12 (50:50, v/v) supplemented with 15\% heat-inactivated fetal bovine serum, bovine insulin $(5 \mu \mathrm{g} / \mathrm{ml})$, cholera toxin $(0.1 \mu \mathrm{g} / \mathrm{ml})$, recombinant human epidermal growth factor $(10 \mathrm{ng} / \mathrm{ml})$, and gentamicin $(40 \mu \mathrm{g} / \mathrm{ml})$ all purchased from Fisher Scientific, UK (Connon, C.J. et al., 2006).

\subsection{Preparation of the 3D corneal epithelial model}

Conventional uncompressed collagen gels (UC) were prepared by neutralising $4 \mathrm{ml}$ sterile rattail type I collagen $(2.2 \mathrm{mg} / \mathrm{ml}$ in $0.6 \%$ acetic acid, First link Ltd, UK) in $1 \mathrm{ml}$ modified Eagle's minimum essential medium (Gibco, Uk) and $0.5 \mathrm{ml} 1 \mathrm{M}$ sodium hydroxide (Fisher, UK). The solution was gently mixed and cast into rectangular moulds $(33 \mathrm{~mm} \times 22 \mathrm{~mm} \times 8 \mathrm{~mm})$ prior to gelling at $37^{\circ} \mathrm{C}, 0.5 \% \mathrm{CO}_{2}$ for 30 minutes. Compressed collagen gels (CC) were then prepared by compression of these conventional gels between two layers of nylon mesh ( $50 \mu \mathrm{m}$ mesh size) under 134g for 5 minutes at room temperature (Brown, R.A. et al., 2005) (Figure 1).

\subsection{Expansion of HCE cells on differing substrates; uncompressed collagen gel (UC), compressed collagen gel (CC) and polycarbonate membranes (PM)}

CC and UC gels were transferred into a 12-well tissue culture insert with a polycarbonate membrane (PM) base (Invitrogen, Fisher Scientific UK). The top side of each substrate (CC, UC and PM alone) were coated with laminin $\left(1.5 \mu \mathrm{g} / \mathrm{cm}^{2}\right)$ for 2 hours prior to cell seeding to enhance cell attachment. HCE cells were seeded onto each of the substrates at a density of $1 \times 10^{9} / \mathrm{ml}\left(0.5 \mathrm{ml}\right.$ per well). After 1 week incubation submerged in media at $37^{\circ} \mathrm{C}$ under $5 \% \mathrm{CO}_{2}$ and another 3 days with the level of the media reduced (air-lifted), the resulting stratified corneal epithelial sheets were ready for further examination (Mi, S. et al., 2010a). Relative cell numbers were calculated at the $10^{\text {th }}$ day following stratification of the corneal epithelial sheets by MTT assay (Matsuda, S. et al., 2009). Relative cell number index= ([O.D. of test sample - O.D. of negative control] / O.D. of negative control).

\subsection{Effect of different substrates on cell viability under toxic conditions}


Following an established procedure (Matsuda, S et al., 2009), increasing concentrations of the known ocular irritant sodium lauryl sulphate (SLS) were applied drop wise to the surface of the ocular surface models (i.e. HCE cells grown on either CC, UC or PM) and then incubated at $37{ }^{\circ} \mathrm{C}$ under $5 \% \mathrm{CO}_{2}$ for 30 minutes with excess liquid removed by blotting paper. The SLS concentrations used were $0.0125 \%, 0.025 \%, 0.05 \%, 0.125 \%, 0.25 \%, 0.5 \%, 1 \%$ and PBS alone as control $(n=9)$. The cells within the ocular surface models were then washed with fresh media, followed by an MTT solution $(0.5 \mathrm{mg} / \mathrm{ml})$ and incubated for a further 3 hours (Matsuda, $\mathrm{S}$ et al., 2009). Excess MTT solution was removed followed by the addition of isopropanol for 2 hours at room temperature. Finally 15 minutes of gentle agitation was then performed and $200 \mu \mathrm{l}$ aliquots were transferred to a 96 well plate and the optical density (OD) at 540 nm measured using a microtiter plate reader. Isopropanol was used as the blank. The resulting cell viability was expressed as a percentage relative to the PBS control.

\subsection{Scanning electron microscopy (SEM)}

The cells upon the surface of each of the ocular surface models (CC, UC and PM) after 10 days in culture were examined by SEM. Collagen gel samples were prepared as previously described (Mi, S. et al., 2010a). Initially fixed in $2.5 \%$ glutaraldehyde solution for 2 hours at $4{ }^{\circ} \mathrm{C}$ and washed 3 times for 10 minutes with distilled water. Samples were then postfixed with 1\% osmium tetroxide for 2 hours and washed with distilled water 3 times before being passed through a graded ethanol series (50\%, 70\%, $90 \%$ and $100 \%)$, critical point dried and finally sputter coated by Au/Pd. Samples were observed in a scanning electron microscope (FEI Quanta FEG 600, Oragon, USA).

\subsection{Transmission electron microscopy (TEM)}

The samples were prepared as for SEM however after dehydration the ethanol was substituted by propylene oxide then the samples were embedded in agar 100 epoxy resin. Ultrathin sections (50-70nm thick) were collected on naked copper grids, and counterstained for $1 \mathrm{~h}$ with $1 \%$ uranyl acetate and 1\% phosphotungstic acid, then for 20 min with Reynold's lead citrate prior to examination in a JEOL transmission electron microscope (Philips CM20) (Mi, S. et al., 2010a; Watson, M. L. 1958; Venable, J. H. and Coggeshall, R. 1965). 


\subsection{Immunolabelling of ZO-1}

The ocular surface models (CC, UC and PM) were examined by immunofluorescence microscopy to probe for the expression of ZO-1 within the HCE cells using an approach described previously (Chen B, et al., 2010). Samples, after 10 days in culture, were embedded in optimal cutting temperature (OCT, Tissue Tek) compound and frozen at $-80^{\circ} \mathrm{C}$. Prior to immunohistochemistry, cryostat sections 7-10 $\mu \mathrm{m}$ thick were collected onto polylysine coated slides and air-dried for 2 hours. Sections were then fixed at $-20^{\circ} \mathrm{C}$ in $100 \%$ methanol for 15 minutes then $100 \%$ acetone for 5 minutes prior to incubation with 1\% (w/v) bovine serum albumin (Sigma-Aldrich, UK) at room temperature to block non-specific binding. Sections were then incubated overnight at $4{ }^{\circ} \mathrm{C}$ with primary antibody against ZO-1 (1:50, Chemicon, UK). The sections were subsequently incubated for 1 hour at room temperature in fluorescein isothiocyanate (FITC)-labelled secondary antibody (1:50, Sigma-Aldrich, UK). Finally sections were co-stained with propidium iodide (Sigma-Aldrich, UK) and observed by fluorescence microscopy (Carl Zeiss Meditec, Germany).

\subsection{RT-PCR analysis}

The PCR protocol was designed to maintain amplification in the exponential phase. The sequences of the PCR primers (sense and antisense, respectively) were 5'TGCCATTACACGGTCCTCTG-3' and 5'-GGTTCTGCCTCATCATTTCCTC-3' for ZO-1; 5'AGATCGACACCACGCTGCGC-3'and 5'-TGTCACTGGTGCACACGGCC-3' for integrin $\beta 4$; 5'ACCACAGTCCACGCCATCAC-3' and 5'-TCCACCACCCTGTTGCTGTA-3' for glyceraldehyde-3phosphate dehydrogenase (GPDH, internal control).

\subsection{Statistical study}

Cytotoxicity was shown as the mean \pm standard error of percentage cell viability. From three independent experiments subsequent inspection of the means was evaluated using a two-way Anova with a Bonferroni post test to determine degree of significance.

\section{Results}




\subsection{Structural characterisation of the ocular surface models}

Three-dimensional models of the ocular surface were constructed using HCE cells expanded upon three different substrates; polycarbonate membrane (PM), compressed collagen (CC) and uncompressed collagen (UC) gels. The level of HCE cell stratification upon each of the scaffolds is shown in figure 2. Both the CC and PM substrates gave similar levels of cell stratification. However, cells grown on UC gels appeared larger and less compacted when compared to the cells on the other two substrates. The relative cell number upon each of the substrates, after 10 days in culture, which measured by MTT assay, as shown in figure 3 . There were a greater number of cells on the CC gels than on the UC gels, indicating that the CC gel is a better collagen based scaffold for cell growth, however PM supported the largest number of cells.

\subsection{HCE cell ultrastructure following expansion upon different scaffolds}

SEM was performed to analyse the epithelial surface of the three ocular surface models. The cells appeared flattened with visible tight junctions structures between cells grown on the PM and CC substrates. The surface epithelial cells grown upon the UC substrate were more round, less regularly spaced and did not display any obvious cell-cell junctions (Figure 4).

TEM analysis showed that HCE cells, after expansion upon PM or CC substrates, displayed evidence of cell-cell tight junction formation (Figure 4). Similar structures were not seen between HCE cells on the UC substrate.

\subsection{Effect of SLS on cell viability within different ocular surface models}

Cell viability measurements from the three different ocular surface models, displayed a similar relative dose-dependent effect to increasing SLS concentrations (Figure 5). However, the IC 50 values did differ. The IC 50 concentrations for SLS against cells grown on CC, UC, and PM were $0.076 \%, 0.043 \%$ and $0.030 \%$ respectively. Cell viability was predominately higher at each SLS concentration for cells grown on the CC substrate. Significance values of $p=0.05, p=0.001$ and $p=0.01$ between CC and PM were seen at concentrations of $0.025,0.05$ and $0.125 \%$ SLS 


\subsection{Effect of differing substrates on Integrin $\beta_{4}$ and ZO-1 expression within expanded HCE cells}

Immunohistochemistry results showed greater ZO-1 staining within HCE cells expanded on PC and CC substrates, when compared to HCE cells expanded upon UC substrates (Figure 6). PCR results also indicated that the ZO-1 expression was greatest from cells grown on PM substrate, lower from cells grown on the CC substrate and negative within UC gel model. The same trend was found in integrin $\beta_{4}$ expression, high in the PM model and low in UC gel model (Figure 7).

\section{Discussion}

When engineering a corneal model the substrate should be able to support levels of corneal epithelial cell adhesion, migration, proliferation and stratification that approach the normal cornea (Shah, A et al., 2008). With this in mind several efforts have been made to improve in vitro ocular toxicity testing. For example chorioallantoic membrane, cell-based cytotoxicity methods, reconstituted tissue models and isolated organ culture methods have all been previously suggested (Hagino, S. et al., 1999; Uchiyama, T. et al., 1999; Ohuchi, J. et al., 1999; Zhao, B. et al., 2009; Xu, K.P. et al., 2000). One of the most established models uses HCE immortalized cells expanded upon a polycarbonate membrane at the air-liquid interface and satisfactory results, in concordance with recorded Draize test data, have been obtained against several formulated ubiquitous cosmetic products (Doucet, O. et al. 2006).

The plastic compression of collagen gels has been shown to improve their mechanical properties (Brown, R.A. et al., 2005, Mi, S. et al, 2011) and has subsequently been used as a substrate for stem cells in the construction of an artificial tissues using including the cornea (Mi, S. et al., 2010a; Mi, S. et al., 2010b; Mi, S. et al, 2011). Furthermore our recent results showing how substrate stiffness can influence corneal epithelial differentiation suggest that tissue culture plastic or polycarbonate membranes may not be the most appropriate substrate for the construction of an accurate ocular surface (Jones, RR et al., 2012). Therefore, we investigated whether HCE cells expanded upon a plastically compressed collagen gel could form a useful model to evaluate in vitro the eye irritation potential of chemicals (sodium lauryl sulphate), by 
comparing this substrate to a conventional uncompressed collagen gel and the leading alternative which uses a polycarbonate membrane.

Among the three substrates (models) tested, a similar cell morphology and ultra-structure were detected by both TEM and SEM between the polycarbonate membrane (PM) and compressed collagen (CC) groups. Tight junction structures were identified, by electron microscopy in these two groups only. The ZO-1 staining and PCR analysis further supported this observation, i.e. was positive in CC and PM groups but negative in uncompressed collagen (UC) group. The tight junction is a specialized structure that generally is the most apical structure of the junctional complex of polarized epithelia and endothelia and ZO-1 is a prominent protein within this complex (Harhaj, N.S. and Antonetti, D.A. et al., 2006). We have previously shown a lack of cell-cell contact between primary epithelial cells on UC gels suggesting this observation is not due to the specialized (immortalized) cell line used here (Mi S. et al, 2010b). For ocular surface models, the tight junction structure is very important, as these cell-cell contacts help form a barrier to the diffusion of molecules from the external surface of the cornea to the inner. Our results strongly indicate that the $\mathrm{CC}$ substrate creates a better in vitro model than the UC substrate based on the increased tight junction number, ZO-1 expression and improved cell morphology within the HCE cells. Cell morphology and tight junction number appeared similar between HCE cells on the PM and CC substrates. Likewise expression of Integrin $\beta_{4}$ was also improved on the PM and CC substrates. These integrins plays a key role in the formation and stabilization of hemidesmosomes, junctional adhesion complexes involved in cell-substrate connection (Wilhelmsen, K. et al., 2006). ZO-1 and integrin $\beta_{4}$ expression, as well as relative cell number, was highest in the PM substrate and lowest on the UC substrate. However despite this the IC 50 values indicated that cells grown on the CC substrate were the most resistant to SLS toxicity. We believe that the improved IC 50 level may be due to the cells response to a more biologically relevant substrate (CC gel) leading to a more robust epithelial cell layer. Previously we have shown the similarity in ultra-structure between the cornea and CC gel (Mi S. et al, 2010b). The marked difference in cell number and cell adhesion proteins (ZO-1 and $\left.\beta_{4}\right)$ is likely explained by the phenomena of durotaxis which relates to increased cell proliferation on 
substrates with increased mechanical stiffness (Pelham, R.J. and Wang, Y.-I. 1997) as the PM substrate is the stiffest and the UC gel is the least stiff.

\section{Conclusion}

We successfully constructed three ocular surface models using polycarbonate membrane, compressed collagen gels or conventional uncompressed collagen gels as substrates. The level of SLS irritation on the HCE cells within each of three models showed a concentration dependent reduction in cell viability that was concordant with data obtained from previous studies. According to the Draize test, the percentage viability of epithelial cells once exposed to sodium lauryl sulphate (SLS) is dose-dependent, which has also been verified by rabbit corneal epithelium cell model (Matsuda, S. et al., 2009). In this study, we chose the same seven concentrations. The data from our study indicate that the viability of expanded HCE cells was dependent on substrate composition, and that compressed collagen gels was best at preserving cell viability when exposed to a known toxin. Therefore our study supported the hypothesis that the compressed collagen gels may provide a substrate for a more accurate and sensitive in vitro model when compared to the conventional uncompressed collagen gel model or the commonly used polycarbonate membrane model. The mechanistic reasons underlying this improvement are likely to be due to the ability of compressed collagen gels to accurately mimic both the ultrastructural and mechanical properties of a natural biological substrate.

\section{References}

Araki-Sasaki K, Ohashi Y, Sasabe T, Hayashi K, Watanabe H, Tano Y, Handa H. An SV40immortalized human corneal epithelial cell line and its characterization. Invest Ophthalmol Vis Sci 36, 614, (1995).

Brown, R.A., Wiseman, M., Chuo, C. -B, Cheema, U. \& Nazhat, S.N. Ultrarapid Engineering of Biomimetic Materials and Tissues: Fabrication of Nano- and Microstructures by Plastic Compression. Advanced Functional Materials 15, 1762-1770 (2005). 
Chen B, Mi S, Wright B, Connon CJ. Investigation of K14/K5 as a Stem Cell Marker in the Limbal Region of the Bovine Cornea. PLoS ONE 5(10): e13192 (2010).

Connon CJ, Kawasaki S, Liles M, Koizumi N, Yamasaki K, NakamuraT, Quantock AJ, Kinoshita S. Gene expression and immunolocalisation of a calcium-activated chloride channel during the stratification of cultivated and developing corneal epithelium. Cell Tissue Research 323, 177182 (2006).

Crabb RA, Chau EP, Decoteau DM, Hubel. A Microstructural characteristics of extracellular matrix produced by stromal fibroblasts. Ann Biomed Eng 34:1615-1627(2006).

Discher D.E., David J. Mooney, and Peter W. Zandstra. Growth factors, matrices, and forces combine and control stem cells. Science. June 26; 324(5935): 1673-1677(2009)

Discher, D.E., Janmey, P. \& Wang, Y.-li Tissue Cells Feel and Respond to the Stiffness of Their Substrate. Science 310, 1139 -1143 (2005).

Doillon CJ, Watsky MA, Hakim M, Wang J, Munger R, Laycock N, Osborne R, Griffith M A collagen-based scaffold for a tissue engineered human cornea: physical and physiological properties. Int J Artif Organs 26:764-773(2003)

Doucet, O., Lanvin, M., Zastrow, L. A new in vitro human epithelium model for assessing the eye irritation potential of formulated consumer products. In Vitro and Molecular Toxicology 11, $273-283(1998)$

Doucet O, Lanvin M, Thillou C, Linossier C, Pupat C, Merlin B, Zastrow L. Reconstituted human corneal epithelium: A new alternative to the Draize eye test for the assessment of the eye irritation potential of chemicals and cosmetic products. Toxicology in Vitro 20, 499-512 (2006).

Draize, J.H., Woodard, G \& Calvery, H.O. Methods for the study of irritation and toxicity of substances applied topically to the skin and mucous membranesJournal of Pharmacology and Experimental Therapeutics 82, 377 -390 (1944).

Duan X, Sheardown H. Dendrimer crosslinked collagen as a corneal tissue engineering scaffold: mechanical properties and corneal epithelia cell interactions. Biomaterials 27:4608-4617 (2006)

Engler AJ, Sen S, Sweeney HL, Discher DE. Matrix elasticity directs stem cell lineage specification. 
Cell. 25,126(4):677-89 (2006).

European Commission. ESAC statement on the conclusion of the ICCVAM retrospective study on organotypic in vitro assays as screening tests to identify potential ocular corrosives and severe irritants as determined by US EPA, EU (R41) and UN GHS classifications in a tiered testing strategy, as part of a weight of evidence approach. In: ECVAM (Ed.), European Commission, p. 3(2007).

Gilbert P.M., Havenstrite K.L., KEG Magnusson, A Sacco, NA Leonardi, P Kraft,NK Nguyen, S Thrun, MP Lutolf, and HM Blau. Substrate elasticity regulates skeletal muscle stem cell selfrenewal in culture. Science. 27, 329(5995): 1078-1081(2010).

Hagino S, Kinoshita S, Tani N, Nakamura T, Ono N, Konishi K, limura H, Kojima H, Ohno Y. Interlaboratory validation of in vitro eye irritation tests for cosmetic ingredients. (2) Chorioallantoic membrane (CAM) test. Toxicology in Vitro 13, 99-113 (1999)

Harhaj, N.S. \& Antonetti, D.A. Regulation of tight junctions and loss of barrier function in pathophysiology. The International Journal of Biochemistry \& Cell Biology 36, 1206-1237 (2004).

Janine O, Lorri W, Jessica K, Mohammed E, Timothy M., David V. Crosslinking of collagen gels by transglutaminase. Journal of Biomedical Materials Research Part A, 68A, 756-762 (2004)

Jones, R. R., Hamley, I. and Connon, C. Ex vivo expansion of limbal stem cells is affected by substrate properties. Stem Cell Research 8, 403-9 (2012).

Kato M, Taguchi T, Kobayashi H. An attempt to construct the stroma of cornea using primary cultured corneal cells. J Nanosci Nanotechnol 7:748-751(2007).

Ko, J.-A., Yanai, R. \& Nishida, T. Up-regulation of ZO-1 expression and barrier function in cultured human corneal epithelial cells by substance P. FEBS Letters 583, 2148-2153 (2009)

Li F, Griffith M, Li Z, Tanodekaew S, Sheardown H, Hakim M, Carlsson DJ. Recruitment of multiple cell lines by collagen-synthetic copolymer matrices in corneal regeneration.

Biomaterials 26, 3093-3104 (2005) 
Matsuda, S., Hisama, M., Shibayama, H., Itou, N. \& Iwaki, M. In vitro eye irritancy test of lauryl derivatives using the reconstructed rabbit corneal epithelium model. Toxicology in Vitro 23, 555-560 (2009).

Matthias P. Lutolf,Penney M. Gilbert, and Helen M. Blau. Designing materials to direct stem-cell fate. Nature 26, 462(7272): 433-441(2009).

Mi, S., Chen, B., Wright, B. \& Connon, C.J. Ex vivo construction of an artificial ocular surface by combination of corneal limbal epithelial cells and a compressed collagen scaffold containing keratocytes. Tissue Engineering Part A 16, 2091-2100 (2010a).

Mi, S., Chen, B., Wright, B. and Connon, C. J. Plastic compression of a collagen gel forms a much improved scaffold for ocular surface tissue engineering over conventional collagen gels. Journal of Biomedical Materials Research Part A, 95A (2). pp. 447-453 (2010b).

Mi, S, Khutoryanskiy, VV, Jones, RR, Zhu X, Hamley IW and Connon CJ. Photochemical crosslinking of plastically compressed collagen gel produces an optimal scaffold for corneal tissue engineering. Journal of Biomedical Materials Research Part A, 99A (1). pp. 1-8. ISSN 1549-3296. (2011).

Nguyen DH, Beuerman RW, DeWever B, Rosdy M. Three-dimensional construct of the human corneal epithelium for in vitro toxicology. In Alternative Toxicological Methods, p 147-159, (2003).

Ohuchi J, Kasai Y, Sakamoto K, Ohnuma M, Kitamura M, Kawasaki Y, Kakishima H, Suzuki K, Kuwahara H, Imanishi Y, Tatsumi H, Kotani M, Inoue K, Okumura H, Arashima M, Kurishita A, Kinoshita S, Tani N, Kojima H, Nakamura T, Suzuki K, Ishibashi T, Hori H, Takahashi H, Nishikawa T, Kitano Y, Ohno Y. Interlaboratory Validation of the In Vitro Eye Irritation Tests for Cosmetic Ingredients. (6) Evaluation of MATREX((TM)). Toxicol In Vitro 13, 153-162 (1999).

Pelham, R.J. and Wang, Y.-I. Cell locomotion and focal adhesions are regulated by substrate flexibility. PNAS 94 ( 25), 13661-13665 (1997). 
Rafat M, Li F, Fagerholm P, Lagali NS, Watsky MA, Munger R, Matsuura T, Griffith M. PEGstabilized carbodiimide crosslinked collagen-chitosan hydrogels for corneal tissue engineering. Biomaterials 29, 3960-3972 (2008).

Seaman CW, Whittingham A, Guest R, Warren N, Olson MJ, Guerriero FJ, Adriaens E, De Wever B. An evaluation of a cultured human corneal epithelial tissue model for the determination of the ocular irritation potential of pharmaceutical process materials. Toxicology in Vitro 24, 18621870 (2010).

Shah, A., Brugnano, J., Sun, S., Vase, A. \& Orwin, E. The Development of a Tissue-Engineered Cornea: Biomaterials and Culture Methods. Pediatric Research 63, 535-544 (2008).

Uchiyama T, Akiyama J, Miyai E, Sakamoto K, Takino Y, Ohnuma M, Ohkosi K, Okamoto Y, Morito Y, Kojima H, Okumura H, Sawamura J, Ikeda N, Sumida Y, Chiba K, Makino I, Kawakami K, Yamamoto R, Torishima H, Yanase H, Miyajima A, Sunouchi M, Hayashi M, Ohno Y. Interlaboratory validation of the In Vitro eye irritation tests for cosmetic ingredients (7) evaluation of cytotoxicity test by CornePack((R)). Toxicol In Vitro 13, 163-173 (1999).

Venable, J.H., Coggeshall R. A Simplified Lead Citrate Stain for Use in Electron Microscopy. J Cell Biol 25, 407-408 (1965).

Watson, M.L. Staining of tissue sections for electron microscopy with heavy metals. J Biophys Biochem Cytol 4, 475-478 (1958).

Wilhelmsen K, Sandy H.M. ,Litjens, Sonnenberg A. Multiple Functions of the Integrin $\alpha 6 \beta 4$ in Epidermal Homeostasis and Tumorigenesis. Mol. Cell. Biol. 26 (8),2877-2886 (2006)

Zhao B, Ma A, Martin F, Fullwood, NJ . An Investigation Into Corneal Alkali Burns Using an Organ Culture Model. Cornea: 28, (5) ,pp 541-546(2009). 


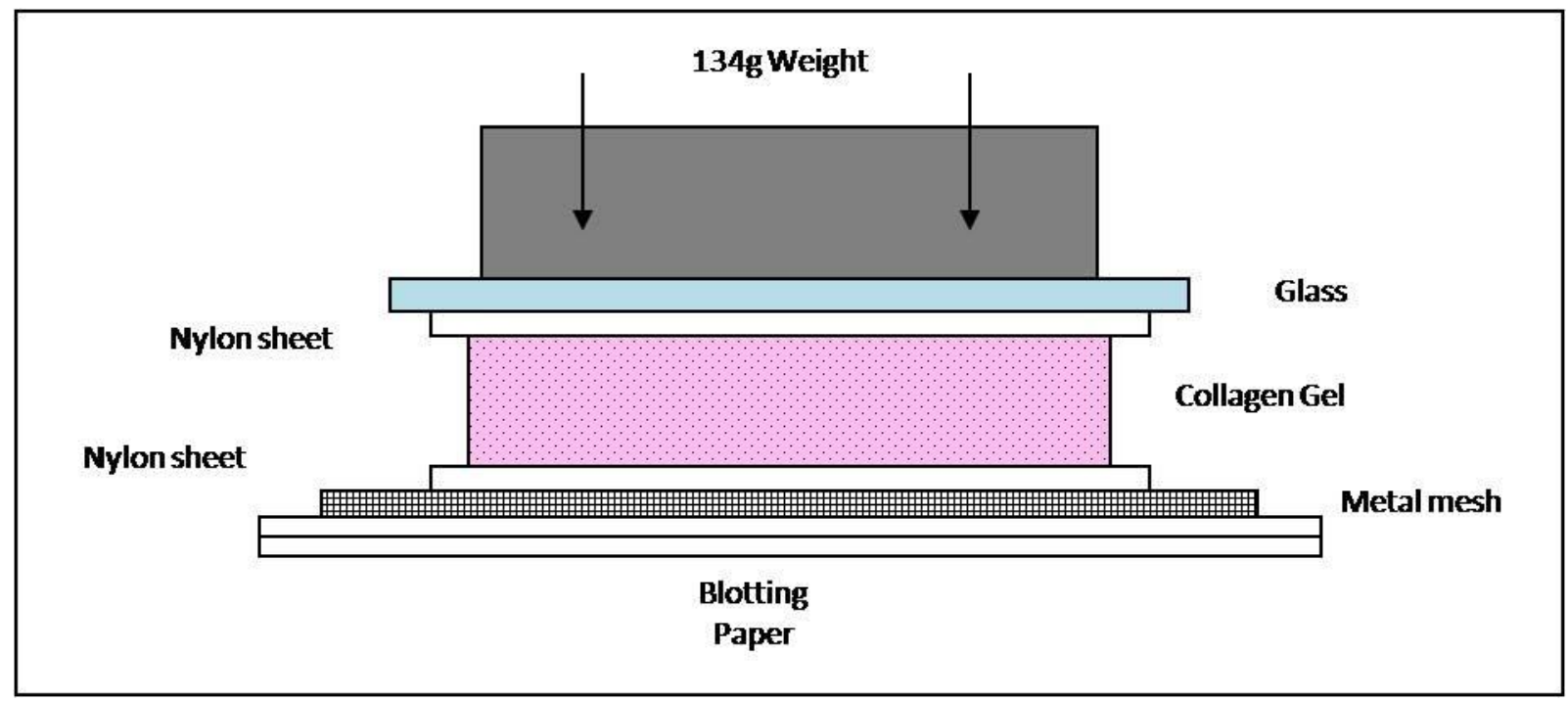

Figure 1: Manufacture of compressed collagen gels.

Schematic showing how the compressed collagen (CC) gel was formed.

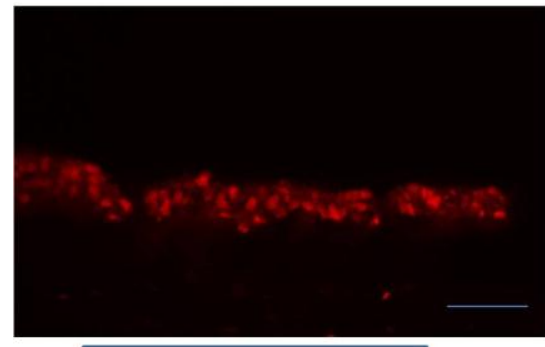

HCE-CC

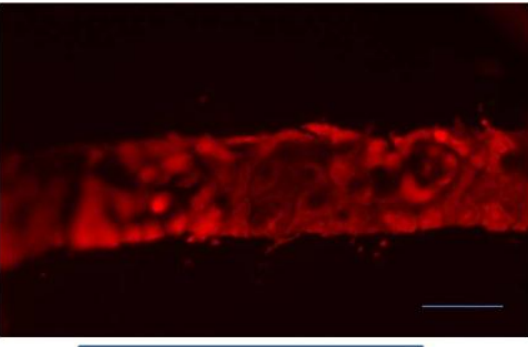

HCE-UC

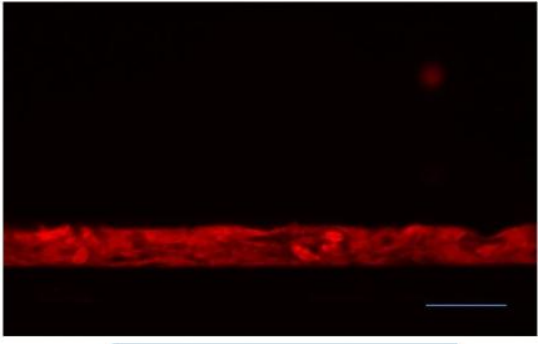

HCE-PM

Figure 2: the PI staining of a histological vertical section of the three different type model

Three-dimensional models of the ocular surface were constructed using HCE cells expanded upon three different substrates; polycarbonate membrane (PM), compressed collagen (CC) and uncompressed collagen (UC) gels. The level of HCE cell stratification upon each of the scaffolds is shown. Both the CC and PM substrates gave similar levels of cell stratification. Scale bar $=50 \mu \mathrm{m}$ 


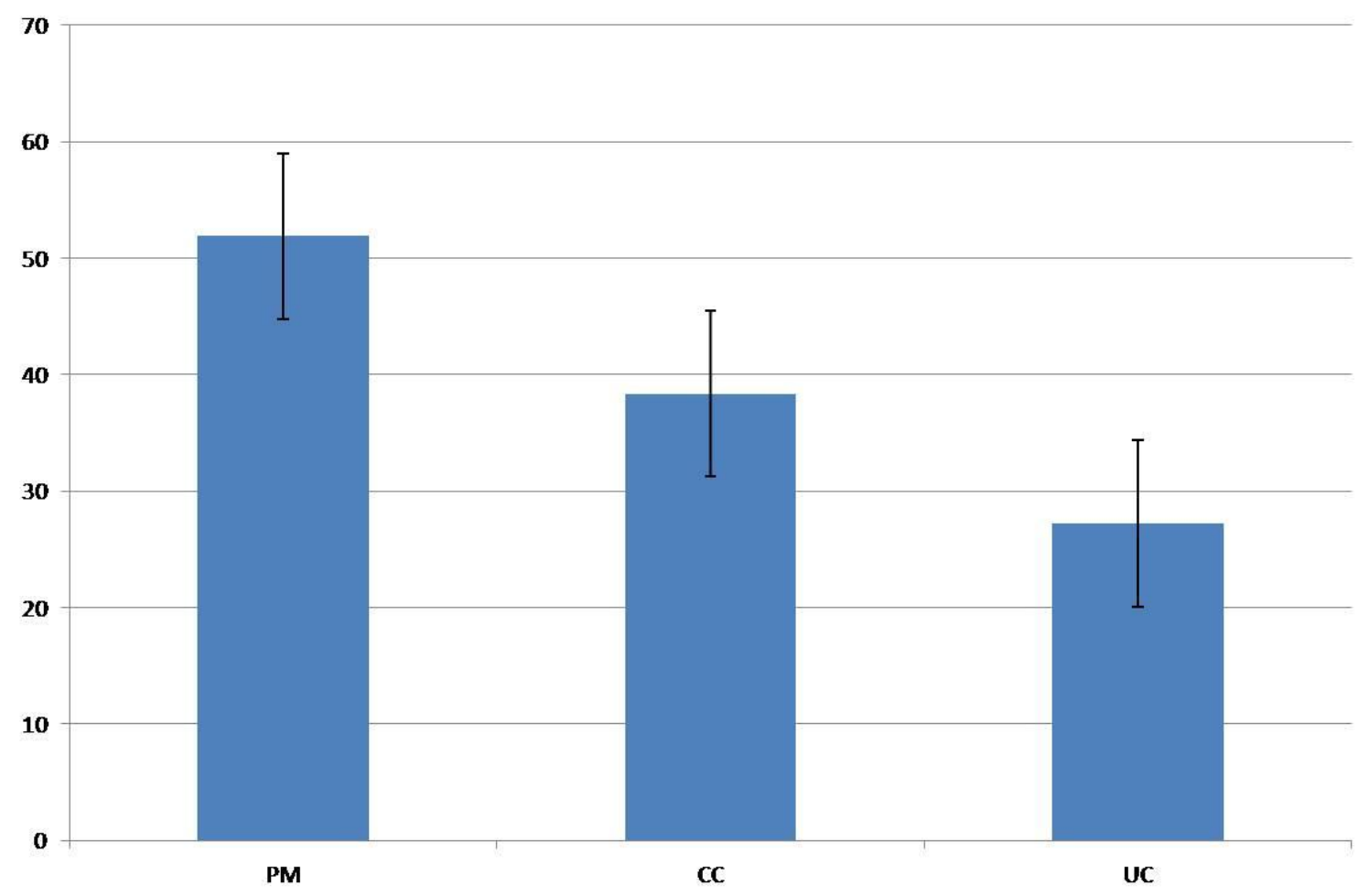

Figure 3: Relative cell numbers of HCE-expanded on PM, CC, UC after 10 days in culture.

Optical density readings from an MTT assay showing an increase in the relative number of epithelial cells expanded upon compressed collagen gels (CC) compared to uncompressed collagen gels (UC). Polycarbonate membrane (PM) supported the largest number of cells among the three type of substrate. 

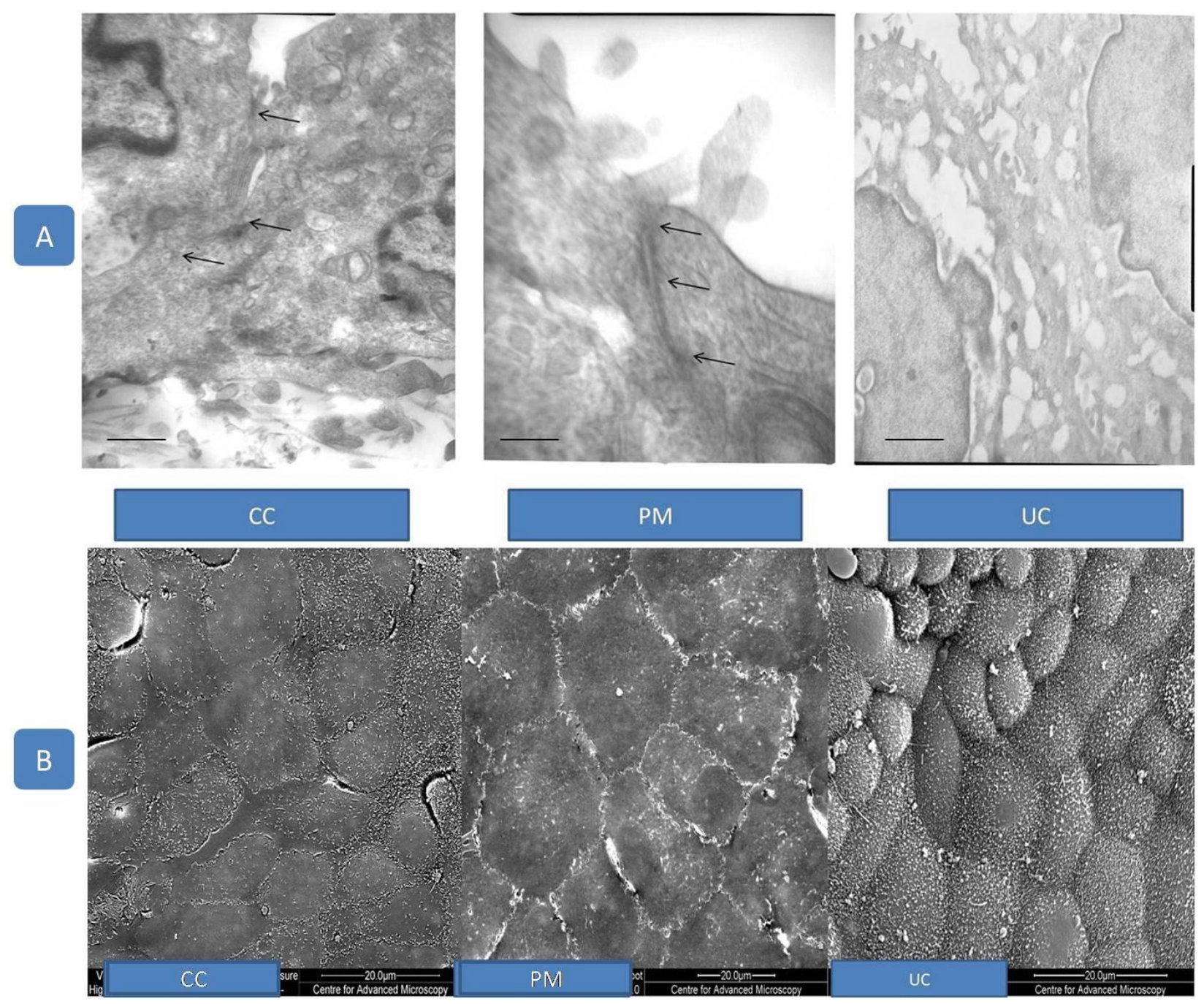

Figure 4: TEM and SEM of the three different ocular surface models

A) TEM showing the tight junctions between the HCE cells expanded upon CC and PM substrates. No similar structure was detected in the HCE expanded upon UC gels. Arrows indicating position of cell-cell junctions. Scale bar $=800 \mathrm{~nm}$.

B) SEM was performed to analyse the epithelial surface of our artificial corneal constructs. It was possible to observe tight junctions on cells grown on the PM and CC surfaces however cells on UC gels were less regularly spaced with no obvious cell-cell junctions. Scale bar $=20 \mu \mathrm{m}$ 


\section{Effect of SLS on cell viability in different corneal models}

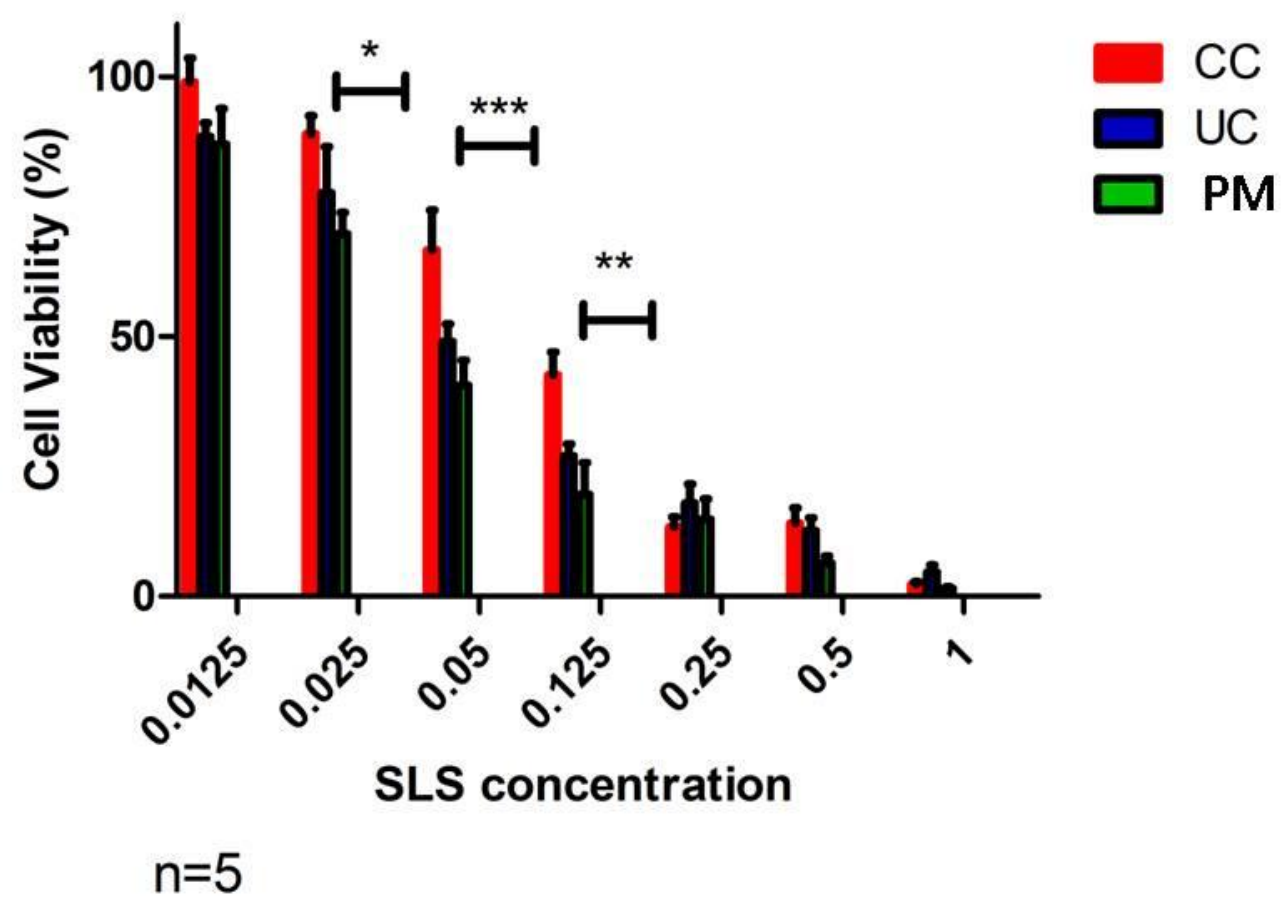

Figure 5: Effect of SLS on cell viability within different ocular surface models

Cell viability measurements from the three different ocular surface models (CC, UC and PM), displayed a similar relative dose-dependent effect to increasing SLS concentrations. However, the IC 50 values did differ. A two-way ANOVA with Bonferonni post test was used to determine significance between cell viability, ${ }^{*}=p<0.05, * *=p<0.01, * * *=p<0.001$. 

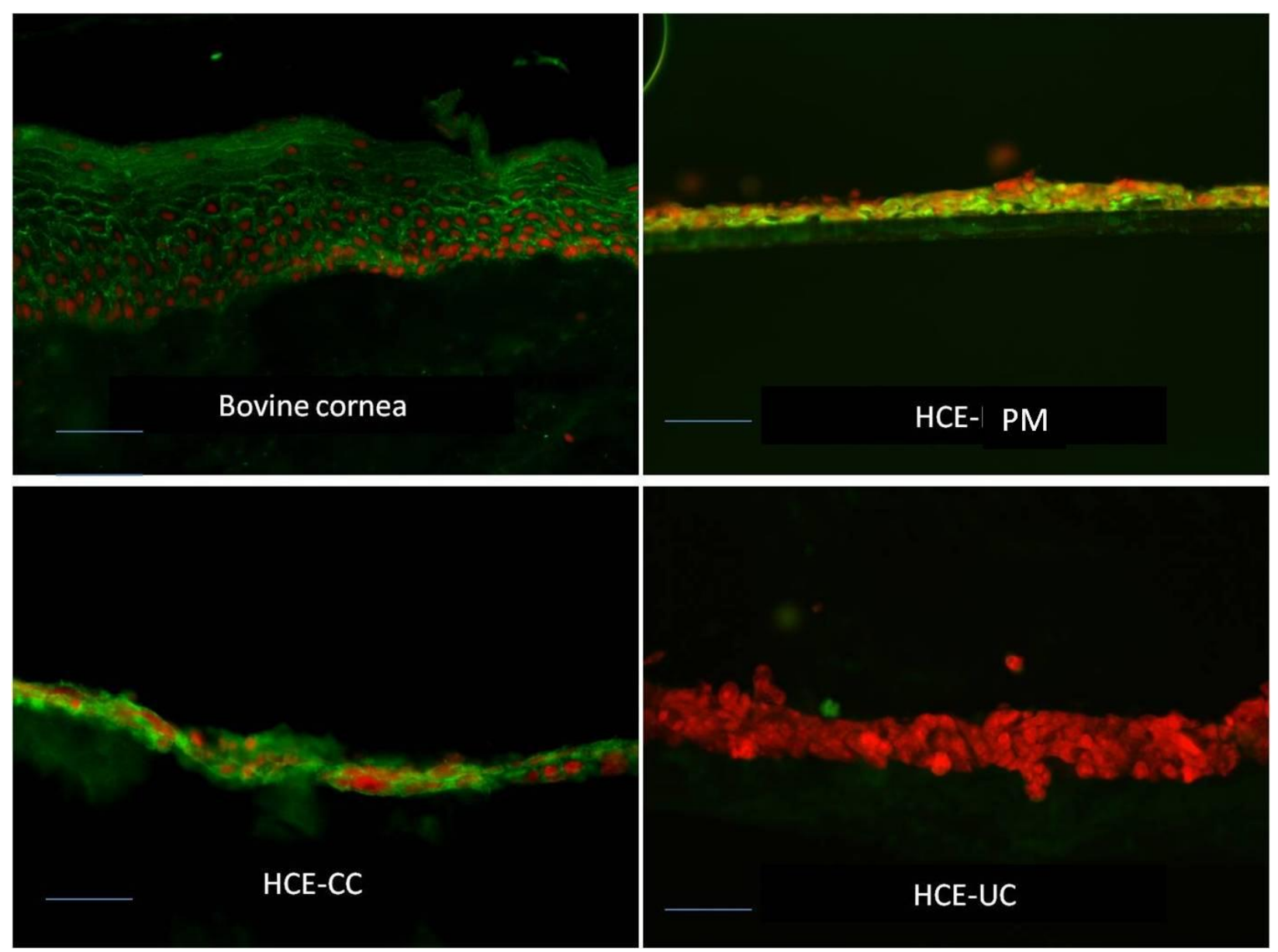

Figure 6: ZO-1 staining (Green = ZO-1, Red = PI), within the three different ocular surface models.

Immunohistochemistry results showed higher ZO-1 staining within HCE cells expanded on either the PM or CC substrates, when compared to HCE cells expanded upon UC substrates. Bovine limbal specimen as positive control. Scale bar=20 $\mathrm{mm}$. 


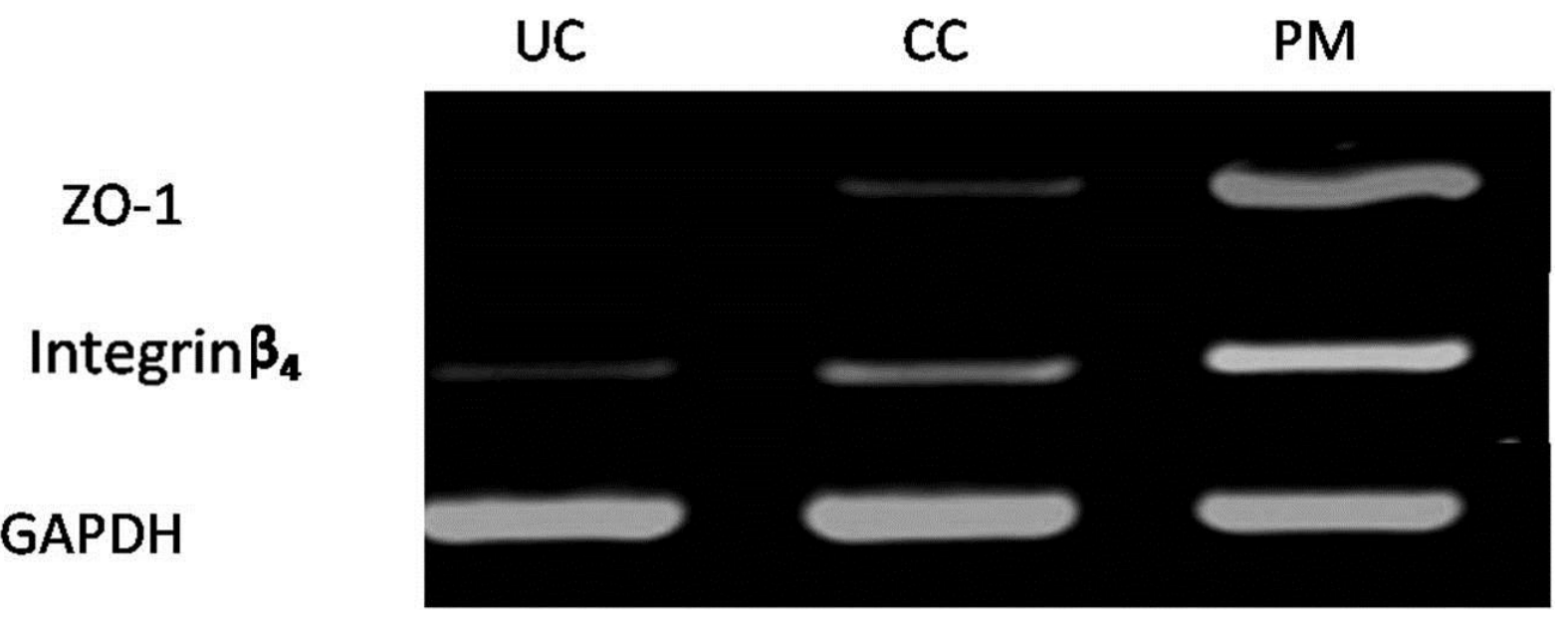

Figure 7: PCR analysis of ZO-1 and Integrin beta 4 within each of ocular surface models

PCR results also showed that the ZO-1 expression was positive in cells grown on PM and CC substrate and negative within cells grown on the UC substrate. The same trend was found in integrin $\beta_{4}$ expression, high in the PM model and low in UC gel model. 
